\title{
Emigration and Wages in an Open Economy: Some Evidence from Pakistan
}

\author{
Zafar MaHmoOd
}

\begin{abstract}
This paper examines the impact of labour emigration on the wages of both the skilled and unskilled workers. The paper is based on a $3 \times 3$ trade-theoretic model, where a subset of the goods produced are traded at internationally fixed prices. The results of the model hinge crucially on the intensitics of the factors used 'within' the traded goods sectors of the economy. Using the Pakistani data, it is found that unskilled labour is used extremely intensively in the agriculture sector (exportable), skilled labour is used extremely intensively in the manufacturing sector (importable), and capital is used as the middle factor in both the traded goods sectors. Moreover, capital is used significantly less intensively in the construction (non-traded) sector relative to both the traded sectors. Based on the estimated relative factor intensities, the model predicts that emigration of either skilled or unskilled workers from Pakistan, in the long run, would benefit (in nominal as well as real terms) both the skilled and unskilled workers and hurt the owners of capital. The results suggest that the higher wages to both the skilled and unskilled workers must be compensated by a reduction in the rate of retums to capital if export-oriented and import-competing sectors in Pakistan are to remain internationally competitive.
\end{abstract}

\section{INTRODUCTION}

Between the mid-1970s and the mid-1980s, there was an exodus of Pakistani workers to the oil-rich OPEC countries. The number of Pakistanis abroad has been estimated between 1.8 and 2.5 million for the year 1984 [see Mahmood (1989)]. This stock roughly accounts for 7 to 8 percent of the domestic labour force. The incidence of emigration found among production workers (consisting of the unskilled and the semi-skilled) is very high ( 81 percent) compared to the rest of the emigrants who are non-production workers (consisting of professionals and technical, managerial, and clerical workers) [see ILO-ARTEP (1984)].

Emigration appears to have affected the whole economy in terms of the labour force participation, investment in human capital, choice of technology, and

The author is Senior Research Economist at the Pakistan Institute of Development Economics, Islamabad.

Author's Note: This paper is based on my Ph.D. dissertation submitted to Columbia University, U. S. A. I am deeply indebted to my dissertation advisers, Professors Jagdish Bhagwati and Asad Zaman, for their invaluable guidance. I would also like to express my appreciation for useful suggestions made by Drs A. R. Kemal and Nadeem A. Bumey towards the final draft of this paper. I wish to thank the Literary Editor of the Review for his excellent editorial help and acknowledge helpful comments made by an anonymous referee of this Review on the earlier drafts. I alone bear responsibility for any errors remaining. 
factor rewards. A study comprehensive enough to account for all these consequences associated with emigration is clearly more relevant for an analysis of the questions pertaining to the labour market, but it represents a tall order. This paper, being limited in scope, confines itself to an examination of the relationship between emigration and wages. We select this relationship because Pakistan experienced the interesting phenomenon of persistently rising wages of both skilled and unskilled workers during the period of recent emigration. For instance, between 1975-76 and 1983-84, the ovcrall (per annum) average real wage of unskilled workers rose by 3.26 percent, and that of skilled workers rose by 0.9 percent.

The impact of emigration on the wages of the skilled and unskilled workers and return to physical capital has never been examined in empirical studies dealing with migration or wage determination in Pakistan. Perhaps, all these studies believed in the predictions of the standard trade-theoretic models - that migration to or from a small open economy should have no effect on the wages of factors of production. The standard trade-theoretic models, however, exhibit important links between trade and factor flows. ${ }^{1}$

Recent models of migration [sce Djajic (1986); Lundahl (1985) and RiveraBatiz (1982)], which incorporate the role of non-traded goods, are able to show the changes in wage due to migration. ${ }^{2}$ Such models, although quite realistic in nature, consider only homogenous labour. The assumption of a homogenous labour is quite restrictive and, as such, these models do not provide much insight into the kind of phenomenon observed in Pakistan.

A model which explains a relationship between emigration and wages of both skilled and unskilled workers, in the presence of both traded and non-traded goods, is clearly more relevant for explaining the pattern of wages that persisted in Pakistan between the mid-1970s and the mid-1980s.

Such a model of migration has been put forward by Kuhn and Wooton (1987) (heniceforth KW). To capture the rcalistic features of the economy KW divide the economy into a non-traded goods scctor and two traded goods sectors; namely, exportable and importable. Traded goods are transacted at internationally fixed prices. With three factors of production, namely, skilled workers, unskilled workers, and capital, the KW model helps to analyze the impact of emigration on factor rewards. Such a formulation allows us to assess whether the interests of various factors of production in migration issues coincide or conflict.

In this paper, we follow the $\mathrm{KW}$ model $^{3}$ to derive empirical conditions, using

${ }^{1}$ Samuelson (1948) showed that international trade substitutes perfectly for international factor mobility.

${ }^{2}$ Bhagwati and Hamada (1974) showed effects on factor earnings in the standard trade-theoretic model by introducing policy-imposed and factor-market distortions.

${ }^{3}$ The difference between the KW model and the model outlined here is that the KW model deals with immigration-wage relationship while we deal with emigration-wage relationship. 
Pakistani data to explain the relationship between emigration and the wages of both skilled and unskilled workers.

The KW model assumes full employment in the economy. It may be argued that in an economy where open unemployment or under-employment prevails, the application of a model of full-employment may give misleading results. However, the low rates of open unemployment and the declining rate of under-employment coupled with rising wage rates in Pakistan suggest that the model can be used with a fair degree of confidence. It may be noted that the open unemployment rate has ranged between 2 and 3 percent since 1974. The low rates of open unemployment confirm the fact that a few barriers to the movement of labour exist between various sectors of the economy. In the Seventies, there was a decline in the underemployment rate. The under-employment rates in the manufacturing and construction sectors, in particular, fell respectively from 16.6 percent and 17.4 percent in 1971-72 to 7.7 percent and 3.9 percent in 1978-79; and there was a rise to 8 percent and 9.4 percent in 1982-83 [sec Government of Pakistan (1971-72 to 1983-84)]. Besides these facts about the unemployment and under-employment situation, a tightening of the labour market can also be inferred from an overall (per annum) increase of 3.19 percent in the real wages of all sectors of the economy over the period 1970-71 and 1983-84.

The schematic details of the study are as follows. Section II describes the model. Empirical methodology is discussed in Section III. Empirical results are presented in Section IV. Section V summarizes the results of the study. Finally, the data issues are discussed in a data appendix.

\section{THE MODEL}

We assume that the labour exporting country is a small open economy producing two tradables: an agricultural good (exportable, $X_{1}$ ) and manufacturing good (importable, $X_{2}$ ), and a non-traded good (construction, $X_{3}$ ), according to linearly homogenous production functions. Each good is produced using the services of three factors of production; namely, unskilled (production) workers $\left(V_{1}\right)$, skilled (non-production) workers $\left(V_{2}\right)$, and capital $\left(V_{3}\right){ }^{4}$

Let $W_{1}, W_{2}$, and $W_{3}$ be the flexible prices (permitting full employment) of the three factors. The amount of factor $i$ used in a unit of good $j$ depends on $W_{i}$, i.e. $a_{i j}=a_{i j}\left(W_{i}\right)$.

Using the estimated relative factor intensities, reported in Table 2, we define

${ }^{4}$ Because of ready availability of the data, the distinction used in this study is between the production and non-production workers. Using the Labour Force Surveys, we have re-classified skilled and unskilled workers belonging to the agriculture, manufacturing, and construction sectors as production and non-production workers. 
the extreme and middle factors in the traded goods sectors as:

$$
a_{22} / a_{21}>a_{32} / a_{31}>a_{12} / a_{11}
$$

Thus, using Ruffin's (1981) terminology, skilled workers are extremely intensive in manufacturing, unskilled workers are extremely intensive in agriculture, and capital is the middle factor in traded sectors.

Under the assumption of perfect competition, prices will equal unit costs so that,

$$
\sum_{j=1}^{3} a_{i j} W_{j}=P_{i} \text {, for } i=1,2,3 \quad \ldots \quad \ldots \quad \ldots
$$

where, $P_{1}$ and $P_{2}$ are, respectively, the prices of agriculture and manufacturing goods. The prices of the two tradables are exogenously given due to the small country assumption. The price of the non-traded $\operatorname{good}\left(P_{3}\right)$ is endogenously determined.

In equilibrium, factor endowments are allocated as,

$$
\sum_{j=1}^{3} a_{i j} X_{j}=V_{i}, \text { for } i=1,2,3
$$

In the standard trade-theoretic model, where all the goods prices are exogenously given, Equation (1) will determine the factor prices, and factor prices are independent of the factor endowments - a pure Stolper-Samuelson effect. The price of a non-traded good is, however, endogenously determined. Consequently, when the factor endowments will change, they will influence all the prices of the non-traded goods, which, in turn, will influence the factor rewards.

To complete the model we add to it the demand side. Consider the following 'Hicksian' compensated demand function for the non-traded good $\left(X_{3}\right)$,

$$
C_{3}=D\left[P_{1}, P_{2}, P_{3} ; U\right] \quad \ldots \quad \ldots \quad \ldots \quad \ldots .
$$

where, $U$ is the economy-wide utility.

The market-clearing condition for the non-traded good is

$$
X_{3}=D\left[P_{1}, P_{2}, P_{3} ; U\right] \quad \ldots \quad \ldots \quad \ldots \quad \ldots \quad \ldots
$$

The economy-wide utility is a function of the consumption bundle,

$$
U=U\left[C_{1}, C_{2}, C_{3}\right]
$$


which is maximized subject both to the balanced trade constraint,

$$
P_{1} C_{1}+P_{2} C_{2}=P_{1} X_{1}+P_{2} X_{2} \quad \ldots \quad \ldots \quad \ldots
$$

and the constraint of technology and endowment,

$$
\begin{aligned}
& X_{3}=G\left[X_{1}, X_{2} ; V_{1}, V_{2}, V_{3}\right] \\
& \text { National income }(I) \text { can be defined } \\
& I \equiv \sum_{i=1}^{3} W_{i} V_{i} \equiv \sum_{j=1}^{3} P_{j} X_{j}
\end{aligned}
$$

\section{Factor Emigration}

Before we analyze the comparative statics of factor rewards, we derive equations of change by differentiating Equations (1) and (2). Let a hat $(\wedge)$ indicate the relative change in a variable or parameter. The equations in the rates of change are shown in Equations (9) and (10),

$$
\theta_{1 j} \hat{W}_{1}+\theta_{2 j} \hat{W}_{2}+\theta_{3 j} \hat{W}_{3}=\hat{P}_{j}, \text { for } j=1,2,3 \quad \ldots \quad \ldots
$$

where, $\theta_{i j} \equiv a_{i j} W_{i} / P_{j}$ is factor $i$ 's distributive share in the $j$ th sector.

Following Jones and Scheinkman (1977), we write Equation (2) as

$$
\lambda_{i 1} \hat{X}_{1}+\lambda_{i 2} \hat{X}_{2}+\lambda_{i 3} \hat{X}_{3}=\hat{V}_{i}-\left[\sigma_{i}^{1} \hat{W}_{1}+\sigma_{i}^{2} \hat{W}_{2}+\sigma_{i}^{3} \hat{W}_{3}\right] \ldots
$$

where, $\lambda_{i j} \equiv a_{i j} X_{j} N_{i}$, the fraction of the total supply of factor $i$ used in the $j$ th sector; $\sigma_{i}^{k}=\sum_{j=1}^{3} \lambda_{i j} E_{i j}^{k}$, where, $\sigma_{i}^{k}$ denotes the economy-wide substitution towards or away from the use of factor $i$ when the return to the $k$ th factor rises at unchanged outputs and $E_{i j}^{k}$ is the elasticity of demand for factor $i$ with respect to $W_{k}$ in industry $j$, holding outputs and other factor prices unchanged.

With the assumption that all goods prices are exogenously given, all the bracketed terms on the right-hand side of Equation (10) would vanish, as there would be no factors substitution. However, outputs would respond to changes in factor endowments only by the relative factor intensities in each sector - a pure Rybczynski effect. In the presence of a non-traded good, however, the factor migration will induce changes in its demand and supply. These changes in turn lead to factor substitution.

Differentiating Equation (5), and using Equations (6) and (7), to determine the change in utility resulting from factor migration at constant commodity prices, 


$$
\hat{U}=\omega \sum_{i=1}^{3} \psi^{i} \hat{V}_{i}
$$

where, $\omega=\rho / / U, \rho=$ marginal utility of money income and $\psi^{i}=W_{i} V_{i} / I$, is the share of factor $i$ in national income. ${ }^{5}$

In order to determine the equilibrium response to changes in the non-traded good market, we differentiate Equation (4),

$$
\hat{X}_{3}=\gamma_{1} \hat{P}_{1}+\gamma_{2} \hat{P}_{2}+\gamma_{3} \hat{P}_{3}+\mu \hat{U}
$$

where, $\gamma_{i}$ 's are compensated price elasticities and $\mu$ is the income elasticity of demand for the non-traded good. Substituting Equation (12) in Equation (11) we have,

$$
\hat{P}_{3}=\beta_{1} \hat{P}_{1}+\beta_{2} \hat{P}_{2}+\beta_{3} \hat{X}_{3}+\phi\left(\psi^{1} \hat{V}_{1}+\psi^{2} \hat{V}_{2}+\psi^{3} \hat{V}_{3}\right)
$$

where, $\beta_{1} \equiv-\gamma_{1} / \gamma_{3}, \beta_{2} \equiv-\gamma_{2} / \gamma_{3}, \beta_{3} \equiv 1 / \gamma_{3}<0$, and (if $X_{3}$ is a normal good) $\phi \equiv-\mu / \gamma_{3}$ $>0$.

Solving the sub-system (10) for $\hat{X}_{3}$,

$$
\hat{X}_{3}=\sum_{i=1}^{3}\left[\delta_{i} \hat{V}_{i}+\Gamma_{i} \hat{W}_{i}\right]
$$

where

$$
\begin{aligned}
& \Gamma_{k}=-\left(\delta_{1} \sigma_{1}^{k}+\delta_{2} \sigma_{2}^{k}+\delta_{3} \sigma_{3}^{k}\right), \text { for } k=1,2,3 \quad \ldots \quad \ldots \\
& \delta_{k}=\left|\lambda_{k}\right| /|\lambda| \text {, for } k=1,2,3 \text {; } \\
& \left|\lambda_{1}\right|<0,\left|\lambda_{2}\right|<0 \text {, and }\left|\lambda_{3}\right|>0 \quad \ldots \quad \ldots \quad \ldots
\end{aligned}
$$

signs of these minors follow from our definition of the extreme and middle factors. From Equation (14), a pure Rybczynski effect can be derived as

$$
\hat{X}_{3}=\sum_{i=1}^{3} \delta_{i} \hat{V}_{i}
$$

Substituting $P_{3}$ from Equations (9) and (14) into Equation (13), and solving we get,

$$
\sum_{i=1}^{3} A_{i} \hat{W}_{i}=\sum_{i=1}^{2} \beta_{i} \hat{P}_{i}+\sum_{i=1}^{3} Z_{i} \hat{V}_{i} \quad \ldots \quad \ldots \quad \ldots
$$

where,

SWith the appropriate choice of utility scale let $\omega=1$ locally, 


$$
\begin{aligned}
& A_{i}=\left(\theta_{i 3}-\beta_{3} \Gamma_{i}\right) \text {, for } i=1,2,3 \quad \ldots \quad \ldots \quad \ldots \\
& Z_{i}=\beta_{3}\left(\delta_{i}-\mu \psi^{i}\right) \text {, for } i=1,2,3 \quad \ldots \quad \ldots . \quad \ldots
\end{aligned}
$$

Assuming $\hat{P}_{1}=\hat{P}_{2}=0$ and using Equations (2) and (18), we examine the induced change in factor rewards when factor endowments change by,

$$
\hat{W}_{k}=\left|\theta_{k}\right| / \Delta\left[\sum_{i=1}^{3} Z_{i} \hat{V}_{i}\right] \text {, for } k=1,2,3 \quad \ldots
$$

where,

$$
\begin{aligned}
& \Delta=\left|\begin{array}{ccc}
\theta_{11} & \theta_{21} & \theta_{31} \\
\theta_{12} & \theta_{22} & \theta_{23} \\
A_{1} & A_{2} & A_{3}
\end{array}\right| \\
& \left|\theta_{1}\right|<0,\left|\theta_{2}\right|<0,\left|\theta_{3}\right|>0 .
\end{aligned}
$$

A pure Stolper-Samuelson effect, where all commodities are internationally traded, can be expressed as

$$
\hat{W}_{k}=\left|\theta_{k}\right| / \theta \mid \hat{P}_{3}, \text { for } k=1,2,3 \quad \ldots \quad \ldots \quad \ldots
$$

where,

$$
|\theta|=\left|\begin{array}{ccc}
\theta_{11} & \theta_{21} & \theta_{31} \\
\theta_{12} & \theta_{22} & \theta_{32} \\
\theta_{13} & \theta_{23} & \theta_{33}
\end{array}\right|
$$

\section{A Decomposition}

Two effects can be noted from Equation (21). One of these effects is the ratio of two determinants. The non-traded good faces an elasticity of demand which is less than infinite. Consequently, changes in factor rewards have repercussions on the supply of $X_{3}$, through within-sector substitution among factors, and this will induce a further change in the commodity price. This the effect is captured by the term $\beta_{3} \Gamma_{i}$ in $A_{i}$ 's involved in the determinant. We label the ratio $\left|\theta_{k}\right| / \Delta$ as the modified Stolper-Samuelson effect.

Following Jones and Scheinkman (1977), KW showed for a negative semidefinite economy-wide substitution matrix that 


$$
\operatorname{sign}(\Delta)=\operatorname{sign}\left(\begin{array}{lll}
\mid & \theta & \mid
\end{array}\right)
$$

implying that $|\theta| / \Delta$ is always positive, and concluded that the modified StolperSamuelson effect will be qualitatively identical to the pure Stolper-Samuelson effect.

The second effect involved in Equation (21) is the $Z_{i}$ term, which gives the effect of emigration $\left(\hat{V}_{i}<0\right)$ on the price of the non-traded good. To emphasize this point we reconsider Equation (20). From Equation (17) we know that $\delta_{i}$ is the supply effect of the change in the output of $X_{3}$ resulting from the emigration of factor $i .^{6}$ The term $\mu \psi^{i}$ is a demand effect, reflecting changes in the demand for $X_{3}$ due to changes in the national income. The difference between the supply and the demand may be labelled as the modified Rybczynski effect. If we have a negative pure Rybczynski effect $\left(\delta_{i}<0\right)$, then there will undoubtedly be an excess demand for the non-traded good, inducing an increase in its price. On the other hand, if $\delta_{i}>$ 0 and if the change in factor endowments is such that it increases the demand for $X_{3}$, then the potential exists for a perverse demand effect. In other words, with a sufficiently high national income-elasticity of demand for the non-traded good, an increase in the output of $X_{3}$, induced by a change in factor endowment, will be accompanied by an increase in its price.

To rule out the perverse demand effect. KW developed a pair of sufficient conditions which are termed as the normality condition. One of these conditions is a fairly weak restriction on the structure of demand, while the other is a constraint on the supply effects which is satisfied by our empirical evidence on factor intensities. Together they imply,

$$
\operatorname{sign}\left(\delta_{i}-\mu \psi^{i}\right)=\operatorname{sign}\left(\delta_{i}\right)
$$

that is the modified Rybczynski effect is qualitatively the same as the pure Rybczynski effect.

Let us express Equation (16) in terms of the distributive shares,

$$
\delta_{i}=\psi^{i}\left|\theta_{i}\right| / \Omega_{3}|\theta|
$$$$
\begin{array}{lll}
\cdots & \cdots & \cdots
\end{array} \quad \cdots
$$

where, $\Omega_{j} \equiv P_{j} X_{j} / I$, the share of good $j$ in the national income. From our numbering of the factors in terms of relative intensity of their use in the traded sectors, we can write

$$
\operatorname{sign}\left(\delta_{1}\right)=\operatorname{sign}\left(\delta_{2}\right)=-\operatorname{sign}\left(\delta_{3}\right) \quad \ldots \quad \ldots \quad \ldots \quad \ldots
$$

${ }^{6}$ Depending on the factor intensity of the non-traded good, $\delta_{i}$ can be either positive or negative. 
It can be inferred from here that the emigration of either of the two extreme factors will have opposite effects from the emigration of the middle factor on the production of $X_{3}$.

Since $\left|\theta_{3}\right|>0$, we can note that

$$
\operatorname{sign}\left(\delta_{3}\right)=\operatorname{sign}(|\theta|) \quad \ldots \quad \ldots \quad \ldots \quad \ldots \quad \ldots
$$

Thus by Equations (26) and (27), the signs of all the Rybczynski effects hinge on whether the non-traded good uses the middle factor more intensively or cannot be compared to either of the two traded goods.?

Next, assume that $X_{1}$ and $X_{2}$, jointly, are not inferior in demand; in the sense that the total expenditure on the two traded goods $\left(P_{1} X_{1}+P_{2} X_{2}\right)$ does not decline when the national income increases at constant prices. Differentiating Identity (8) and substituting $\mu=X_{3} / I$ gives,

$$
\psi^{i} / \Omega_{3}>\mu \psi^{i}
$$

Thus the non-inferiority of $X_{1}$ and $X_{2}$ ensures that the demand term modifying the Rybczynski effect is less than the income of emigrating factor relative to the value of output of $X_{3}$. We, thus, rule out the perverse demand effect if $\delta_{i}>\psi^{i} / \Omega_{3}$. Using Equation (25) this implies

$$
\left|\theta_{i}\right| /|\theta| \geq 1
$$

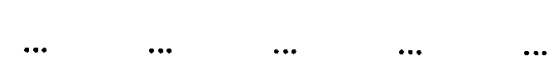

Consider that the emigration of skilled workers $\left(\hat{V}_{2}\right)$ increases the output of $X_{3}$, i.e., $\delta_{2}<0$. From Equation (25) it implies that $|\theta|>0$ since $\left|\theta_{2}\right|<0$. Since both $\left|\theta_{1}\right|$ and $\left|\theta_{2}\right|$ are negative, we are assured that $\left|\theta_{3}\right|>|\theta|$ and, hence, the perverse demand effect cannot occur.

If, instead, the emigration of skilled workers reduces the output of $X_{3}$, i.e., $\delta_{2}$ $>0$, then the potential for a perverse demand effect arises after emigration. Now as $|\theta|<0$ and only $\left|\theta_{3}\right|>0$, it is not possible to rule out $\left|\theta_{j}\right| /|\theta|<1$ for $j=1$ or 2. The reason is that, with the emigration of either kind of labour, the output of the non-traded good declines along with a fall in its demand; if the fall in the demand

$$
\begin{aligned}
& { }^{7} \mathrm{~A} \text { sufficient condition for } \delta_{3}>0 \text { is, then, that } \\
& \qquad \theta_{32} / \theta_{33}<\theta_{12} / \theta_{13}, \theta_{22} / \theta_{23} \text { or } \theta_{31} / \theta_{33}<\theta_{11} / \theta_{13}, \theta_{21} / \theta_{23}
\end{aligned}
$$

It says that $X_{3}$ is much more capital-intensive than either $X_{1}$ or $X_{2}$. Therefore, an increase in the supply of, say, $V_{2}$ raises the output of $X_{3}$. Conversely, if $X_{3}$ is significantly less capital-intensive relative to either one of the traded goods, the supply of $X_{3}$ will fall when a reduction in $V_{2}$ takes place. 
is greater than the fall in the output, then its price decreases and we can end up with a perverse demand effect even when both traded goods are jointly non-inferior. The normality condition, therefore, in general, requires both $\mu \Omega_{3}<1$, which ensures a small enough effect of emigration on the demand of non-traded good, and $\left|\theta_{i}\right||| \theta \mid>1$ for $|\theta|<0$ and $j=1$ or 2 , which ensures a large enough supply effect in the cases where the non-traded good is significantly less intensive in capital.

Under the normality condition we can show that the Rybczynski effect has the same sign as the Stolper-Samuelson effect - the so-called Reciprocity Condition,

$$
\operatorname{sign}\left(\delta_{i}\right)=\operatorname{sign} \mid \begin{array}{llllll}
\theta & \theta / \Delta & \ldots & \ldots & \ldots & \ldots
\end{array} \quad \ldots
$$

Substituting Equations (24) and (30) into Equation (21) and noting that $\beta_{3}<$ 0 , we get,

$$
\operatorname{sign}\left(\hat{W}_{k}\right)=\operatorname{sign}\left(-\delta_{k} \delta_{i} \hat{V}_{i}\right), \text { for } i, k=1,2,3 \quad \ldots \quad \ldots
$$

Equation (31) says that irrespective of whether $|\theta| \gtrless 0$, any factor is its own friend, that is, emigration raises its earnings. Furthermore, as $\delta_{1}$ and $\delta_{2}$ have the same sign, the extreme factors, skilled and unskilled workers when the emigration is taking place, will be mutual friends while being enemies of the capital. The qualitative effects of the factor quantities on the factor prices, thus, depend only on which factors are extreme in traded sectors, and not on the relative factor intensities of the traded versus non-traded sectors. The reason: whenever a factor supply shift raises the price of the non-traded good (by, say, lowering its supply), higher nontraded good price lowers the equilibrium price of the factor, and vice versa.

The effect of the labour emigration on the nominal wages of all three factors is clear from Equation (31). However, it is not clear whether real wage of both extreme factors always moves in the same direction. To see this, we use Equation (22) in Equation (21).

$$
\hat{P}_{3}=\beta_{3}|\theta| / \Delta\left(\delta_{i}-\mu \psi^{i}\right) \hat{V}_{i} \quad \ldots \quad \ldots \quad \ldots \quad \ldots
$$

Let us write the relative change in the ratio of wage of factor $k$ to the price of good 3 as

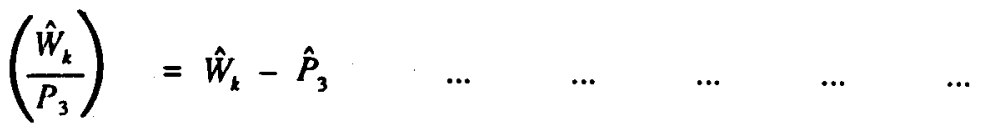


substituting Equations (32) and (21) into Equation (33) and rearranging we get,

$$
\left(\frac{\hat{W}_{k}}{P_{3}}\right) \quad=\hat{P}_{3}\left(\left|\theta_{k}\right| /|\theta|-1\right) \ldots \quad \ldots \quad \ldots \quad \ldots
$$

The bracketed term on the right-hand side of Equation (34) is positive if Equation (29) holds. This implies that the change in the nominal wage will outweigh the change in the price of the non-traded good. Ensuring changes in the real wages will have the same signs as the changes in the nominal wages. Thus, independently of whether the price of the non-traded good rises or falls as a result of emigration, we get unambiguous signs for the real wages.

\section{EMPIRICAL METHODOLOGY}

In order to see how the model predicts the pattern of wages that has persisted during the period of the exodus of workers from Pakistan, we estimate the parameters of the model.

Our estimates of the parameters are based on three major sectors of Pakistan's economy: agriculture, large-scale manufacturing (henceforth manufacturing), and construction. Selection of these three sectors is dictated by the availability of data on these sectors, and the fact that the majority of the emigrants belong to these sectors. ${ }^{8}$ We consider agricultural goods as exportables and manufacturing goods as importables because Pakistan is a net exporter of agricultural goods and a net importer of manufacturing goods. Construction is treated as a nontraded activity. 9

For the present study, we consider four different periods to reflect various phases of emigration. The year 1970-71 is chosen to study the behaviour of wages in the pre-emigration period. This year is also selected because for five years thereafter no Census of Manufacturing Industries (CMI) was conducted. The year 1976-77 marks the period when a large number of workers started emigrating from Pakistan. To reflect the peak of emigration, 1980-81 is chosen. Finally, 1983-84 is chosen to capture the effects of return emigration. ${ }^{10}$

To estimate the factor intensities, the basic procedure is to allocate the total value-added in each sector to payments to the three factors of production. Based on the wage data for skilled and unskilled workers reported in Table 4, and their

\footnotetext{
${ }^{8}$ These three sectors, in 1983-84, jointly accounted for 54 percent of the GDP and employed about 69 percent of total labour force.

The share of the non-tradables in total GDP during 1983-84 was 56 percenl. Out of this, the share of the construction sector was 10 percent.

${ }^{10}$ We report all the data issues in the appendix.
} 
employment levels, reported in Govemment of Pakistan (1985) and in various issues of CMI, we compute the total incomes for skilled and unskilled workers for the three sectors of the economy. Finally, we subtract total wage payments to both kinds of workers from total value-added to compute the payments to capital in each sector.

Once we determine the payments to all three factors of production for all three sectors of the economy, it is rather easy to compute the matrices of absoluteand relative-factor intensities. Estimates of the absolute factor intensities are reported in Table 1. Table 1 reveals a very interesting pattern of the factor intensities. It shows that the increase in the share of unskilled workers in total valueadded in the agriculture sector, between the period 1970-71 and 1983-84, is only marginal; it rose from 48 percent to 49 percent, while the shares of skilled workers and capital in the agriculture sector have marginally gone down over the same period. ${ }^{11}$ In the case of the manufacturing sector, the share of unskilled workers in total value-added, between 1970-71 and 1983-84, has gone down from about 17 percent

\section{Table 1}

Estimated Absolute Factor Intensities

\begin{tabular}{ccccc}
\hline Sectors & $1970-71$ & $1976-77$ & $1980-81$ & $1983-84$ \\
\hline
\end{tabular}

Agriculture

Unskilled Workers

Skilled Workers

Capital

$\begin{array}{lllll}\theta_{11} & 0.477 & 0.486 & 0.490 & 0.494 \\ \theta_{21} & 0.002 & 0.002 & 0.001 & 0.001 \\ \theta_{31} & 0.521 & 0.512 & 0.509 & 0.505\end{array}$

Manufacturing

Unskilled Workers

Skilled Workers

Capital

$\begin{array}{ll}\theta_{12} & 0.167 \\ \theta_{22} & 0.049 \\ \theta_{32} & 0.784\end{array}$

0.187

0.144

0.148

0.063

0.052

0.056

0.750

0.804

0.797

\section{Construction}

Unskilled Workers

Skilled Workers

Capital

$\begin{array}{ll}\theta_{13} & 0.575 \\ \theta_{23} & 0.074 \\ \theta_{33} & 0.351\end{array}$

0.766
0.093
0.141

0.907

0.668

0.064

0.268

${ }^{11}$ For the agriculture sector we treat land as synonymous with capital. 
to 15 percent, while the shares of both the skilled workers and capital have marginally improved. On the other hand, in the construction sector, the share of unskilled workers in total value-added, between 1970-71 and 1980-81, has gone up sharply (from 57.5 percent to 90 percent); since then the trend is completely reversed. The share of skilled workers in the value-added has remained virtually stagnant between 1970-71 and 1980-81, and thereafter it went down. ${ }^{12}$ The share of capital in the construction sector has decreased sharply between 1970-71 and 1980-81, but thereafter it sharply increased.

\section{EMPIRICAL RESULTS}

Based on the absolute factor intensitics reported in Table 1, we present the relative factor intensities in Table 2. From Table 2, with the three factors of production, two traded goods, and a non-traded good, we can write the following factor extremity condition

$$
a_{22} / a_{21}>a_{32} / a_{31}>a_{12} / a_{11}
$$

Notice that for any given set of the factor endowments $V_{i}(i=1,2,3)$ and the traded goods prices $P_{j}(j=1,2)$ two of the factors must normally be the cxtreme factors and the third factor must be a middle factor. ${ }^{13}$

Comparing the relative factor intensities of the two traded sectors, it may be noted from row 1 of each year in Table 2 that since 1970-71 the relative factor intensities in Pakistan have followed a consistent pattern: unskilled workers are used extremely intensively in the agriculture sector (exportable) and skilled workers are used extremely intensively in the manufacturing sector (importable), with capital as the middle factor. ${ }^{14}$ These results are in agreement with the widely held notion about a country like Pakistan, that it is well-endowed with unskilled labour, and poorly-endowed with skilled workers relative to the developed countries. And the fact that the low technology structure of industries in Pakistan require a rclatively lower. proportion of skilled workers conıared to unskilled workers.

Rows 2 and 3 for each year, in Table 2, indicate another consistent pattern; that is, the construction sector is significantly less capital-intensive compared to the

${ }^{12} \mathrm{~A}$ word of caution about the year 1980-81. The value-added data for the year 1980-81 of the construction sector is underestimated [See Government of Pakistan (1990)]. Howcver, underestimation does not affect the direction of the signs.

${ }^{13}$ As noted by Ruffin (1981), with changes in the exogenous variables there may be factor extremity reversals.

${ }^{14}$ Mahmood (1989) has extended the same analysis by disaggregating the manufacturing sector and confirmed the results derived in this paper. 
Table 2

Estimated Relative Factor Intensities

\begin{tabular}{cccc}
\hline$\theta_{i j} / \theta_{i k}$ & $V_{1}$ & $V_{2}$ & $V_{3}$ \\
\hline $1970-71$ & & & \\
$\theta_{i 1} / \theta_{i 2}$ & 2.86 & 0.04 & 0.67 \\
$\theta_{i 1} / \theta_{i 3}$ & 0.83 & 0.03 & 1.48 \\
$\theta_{i 2} / \theta_{i 3}$ & 0.29 & 0.66 & 2.23 \\
$1976-77$ & & & \\
$\theta_{i 1} / \theta_{i 2}$ & & & \\
$\theta_{i 1} / \theta_{i 3}$ & 0.60 & 0.03 & 0.68 \\
$\theta_{i 2} / \theta_{i 3}$ & 0.63 & 0.02 & 3.63 \\
$1980-81$ & 0.24 & 0.68 & 5.32 \\
$\theta_{i 1} / \theta_{i 2}$ & & & \\
$\theta_{i 2} / \theta_{i 3}$ & & & \\
$\theta_{i 2} / \theta_{i 3}$ & 3.40 & 0.02 & 0.63 \\
$1983-84$ & 0.54 & 0.01 & 33.93 \\
$\theta_{i 1} / \theta_{i 2}$ & 0.16 & 0.67 & 53.60 \\
$\theta_{i 1} / \theta_{i 3}$ & & & \\
$\theta_{i 2} / \theta_{i 3}$ & & & \\
\hline
\end{tabular}

traded sectors. This implies the following conditions:

and

$$
\theta_{31} / \theta_{33}>\theta_{11} / \theta_{13}, \theta_{21} / \theta_{23}
$$

$$
\theta_{32} / \theta_{33}>\theta_{12} / \theta_{13}, \theta_{22} / \theta_{23}
$$

In conjunction with the results of Section II, these relative factor intensities imply that $|\theta|<0$ and can be confirmed from the estimates reported in Table 3 for the entire period. Using the fact that $|\theta|<0$ Equation (27) implies that $\delta_{3}<0$ because $\left|\theta_{3}\right|>0$. Estimates reported in Table 3 also satisfy the normality condition that $\left|\theta_{j}\right| /|\theta|>1$ for $j=1$ or 2 which ensures a large-cnough effect of emigration on the supply of the construction activity, which is significantly less capitalintensive. Moreover, our estimates verify the condition that $\mu \Omega_{3}<1$ which ensures 
Table 3

Minors and Determinants

\begin{tabular}{lcccc}
\hline Years & $\left|\theta_{1}\right|$ & $\left|\theta_{2}\right|$ & $\left|\theta_{3}\right|$ & $|\theta|$ \\
\hline $1970-71$ & -0.024 & -0.287 & 0.023 & -0.027 \\
$1976-77$ & -0.031 & -0.364 & 0.030 & -0.053 \\
$1980-81$ & -0.026 & -0.321 & 0.025 & -0.048 \\
$1983-84$ & -0.027 & -0.319 & 0.028 & -0.031 \\
\hline
\end{tabular}

a small-enough effect of emigration on the demand for the construction activity. ${ }^{15}$ With the satisfaction of the normality condition, we rule out the perverse demand effect in the present case and can apply the result derived in Equation (31).

Results from Table 3 can be used to show that for all the years $\delta_{1}, \delta_{2}>0$ and $\delta_{3}<0$. These parameters, in conjunction with Equation (31), imply that the emigration of either kind of labour from Pakistan, in the long run, will always benefit both the skilled and unskilled workers, mutual friends by reciprocity, and hurt the owners of capital. The reason is that when emigration takes place, it raises the price of construction (a labour-intensive activity), which, in turn, raises the wages of both the skilled and unskilled workers. Consequently, the higher wages to both the skilled and unskilled workers must be compensated by a reduction in the return to capital if export-oriented and import-competing sectors in Pakistan are to remain internationally competitive. This magnification effect can be noted from the trends of average (national) rate of return to capital and average (national) wage, as reported in Table 4. That is, during the period of emigration, the average wage of both the skilled and unskilled workers increased, and the average rate of return to capital went down. ${ }^{16}$

We conclude the analysis by noting that the estimates reliably confirm the broad underlying pattern of rising wages of both kinds of workers, a pattern which has persisted between the mid-1970s and the mid-1980s, when a large exodus of

${ }^{15}$ We estimate $\mu \theta_{3}$ for the years $1970-71,1976-77,1980-81$, and 1983-84, respectively, as $0.003,0.003,0.003$, and 0.004 .

${ }^{16}$ At the disaggregate level, the magnification effect is not very clear from the rate of retum on capital because it is estimated as a residual. 
Table 4

Annual Real Wages and Rates of Return to Capital in Pakistan

(in Rupees)

Sectors

1970-71

1976-77

1980-81

1983-84

Unskilled Workers

Agriculture

Manufacturing

Construction

Average

$\begin{array}{rrrr}833.0 & 965.0 & 1144.0 & 1189.0 \\ 1544.4 & 1740.1 & 2404.3 & 3077.2 \\ 951.2 & 1470.3 & 1777.7 & 1667.5 \\ 860.9 & 1028.6 & 1228.2 & 1306.7\end{array}$

Skilled Workers

Agriculture

Manufacturing

Construction

Average

Average (National) Wage

833.0

965.0

1144.0

1189.0

3157.5

2485.8

3045.4

3404.8

2235.9

3047.9

3706.2

3332.1

2664.1

2294.6

3198.8

3218.1

886.0

1044.5

1249.9

1333.5

Rate of Returns to Capital

Agriculture

Manufacturing

Construction
0.301

0.308

1.820
0.443

0.211

0.960
0.330

0.242

0.121
0.301

0.211

1.390

(National) Rate of Return to Capital

Source: See data appendix.

Pakistani workers took place. ${ }^{17}$

\section{SUMMARY AND CONCLUSIONS}

An attempt has been made in this study to examine the phenomenon of rising wages of both the skilled and unskilled workers which has persisted in Pakistan

${ }^{17}$ As the construction boom in the Middle East was over shortly after 1980-81, return migration, mostly of the construction workers, staned; its effect can be seen from the falling wages of both the skilled-and unskilled-construction workers. On the other hand, wages of both the agricultural and manufacturing workers kept increasing as they were in demand outside Pakistan. 
between the mid-1970s and the mid-1980s. The rise in the wages of both the skilled and unskilled workers coincided with a period when a large number of Pakistani workers emigrated to the oil-rich OPEC countries.

We followed the KW model to derive the empirical conditions which set out a relationship between emigration and wages of both the skilled and unskilled workers, and the rate of return to capital.

Based on the Pakistani data, it is found that since the beginning of the 1970s factor intensities have followed a consistent pattern: unskilled workers are used extremely intensively in the agriculture sector (exportable), skilled workers are used extremely intensively in the manufacturing sector (importable), and capital is used as the middle factor in both the traded sectors. Moreover, capital is used significantly less intensively in the construction sector relative to both the traded sectors, i.e., agriculture and manufacturing.

Based on the estimated parameters, the model predicts that, given a weak normality condition, emigration of either skilled or unskilled workers from Pakistan, in the long run, would benefit (in nominal as well as real terms) both the skilled and unskilled workers and hurt the owners of capital. Thus, emigration of any kind of workers turns income distribution in favour of labour and against capital. The intuition behind this result is that emigration raises the price of construction (a labour-intensive activity), which in turn raises the wages of both the skilled and unskilled workers. Higher wages to both the skilled and unskilled workers must be compensated by a reduction in the rate of return to capital if export-oriented and import-competing sectors in Pakistan are to remain internationally competitive.

These predictions summarize the broad underlying pattern of rising wage of both the skilled and unskilled workers and a falling rate of retum on capital which has persisted throughout the period Pakistan witnessed an exodus of both skilled and unskilled workers.

Interests of both the skilled and unskilled workers must conflict with those of the owners of capital, as higher wage rewards to the workers must be compensated for by a reduction in the return to capital if Pakistan's exports and importcompeting sectors are to remain internationally competitive. Thus, both the skilled and unskilled workers should favour emigration of labour, capital inflow, and investment out of the workers' remittances, while the owners of capital should adopt an opposite view.

It is important to note that the predictions of this exercise are independent of the technical substitution possibilities among the factors of production. This implies that emigration-induced changes in the international competitiveness of the traded goods, rather than intra-industry substitution among the factors of production, can be the crucial mechanism through which the equilibrium factor rewards 
are altered by emigration. There is also an implied call for the country's traded sectors to remain internationally competitive, in determining the effects of emigration, if a subset of the produced goods are traded internationally.

\section{Data Appendix}

This appendix furnishe the way factor payments are estimated for each sector.

Starting with the agriculture sector, we use the wage data reported in Naqvi et al. (1983) for the period 1970-71 to 1978-79, and ILO (1986) for the period 1980-81 to 1983-84. Total number of employed workers in the agriculture sector are reported in Government of Pakistan (1985). The distribution of employed workers by skilled (non-production) and unskilled (production) categories are reported in Government of Pakistan (1971-72 to 1983-84). Using these data, we compute the wage payments to both the skilled and unskilled workers in the agriculture sector.

Wage data for the agricultural skilled workers are not available. To get the required information about the wage of the skilled agricultural workers, we conducted a survey of a few farmers in the districts of Gujranwala, Toba Tek Singh, and Hyderabad. The survey revealed that a skilled worker (generally a cleric or a sales worker) received wages equivalent to those of an unskilled worker. We utilize this information to compute the wage payments to the skilled workers in the agricultural sector. Once we compute the wage payments to both the skilled and unskilled workers, we subtract these payments from the value-added of the agriculture sector to derive the payments to capital.

For the manufacturing sector, all the required data are available from. Government of Pakistan (Various Issues). Before 1982-83, none of the CMI reported employment costs separately for skilled (non-production) and unskilled (production) workers for total Pakistan. Such data are, however, available for the provinces of Punjab and Sindh. These data are used to compute the employment costs for skilled and unskilled workers for total Pakistan.

For the manufacturing sector, we subtract other costs in addition to the employment costs from total value-added to yicld payments to capital. This is because the value-added data of the manufacturing sector include other costs.

For the construction sector, we utilize the distribution of employed workers for production and non-production categories reported in Government of Pakistan (1971-72 to 1983-84). Production workers involve both skilled (which consists of masons, carpenters, steel fixers, and painters, etc.) and unskilled workers. Wages for skilled and unskilled workers are separately reported in Government of Pakistan 
(1972 to 1985), and not for the production workers as a whole. The division of production workers into skilled and unskilled workers is not available. We conducted a survey of the construction contractors in Lahore and Faisalabad, who revealed that for various kinds and stages of construction they require different ratios of skilled and unskilled workers. However, on average, the ratio of unskilled to skilled workers was around $2: 1$. We utilize this ratio to compute the wage payments to skilled and unskilled production workers in the construction sector.

Wages for the professional, managerial, and clerical construction workers are not available. We utilize the information revealed in the above-mentioned survey of construction contractors regarding the wages of professional, managerial, and clerical workers. According to this information, a professional approximately receives a wage two times that of a mason, while the managerial, clerical, and sales workers receive a wage equivalent to that of a mason. A service worker receives a wage equivalent to that of an unskilled worker. Using these data, we compute the distributive shares of the three factors of production in the construction sector.

\section{REFERENCES}

Bhagwati, J. N., and K. Hamada (1974) The Brain Drain, International Integration of Markets for Professionals and Unemployment: A Theoretical Analysis. Journal of Development Economics $1: 1$ 19-42.

Djajic, S. (1986) International Migration, Remittances and Welfare in a Dependent

Economy. Journal of Development Economics 21 : 2229-234.

ILO (1986) Year Book of Labour Statistics. Geneva: International Labour Organization.

ILO-ARTEP (1984) Impact of Retum Migration on Domestic Employment in

Pakistan: A Prcliminary Analysis. The Asian Employment Programme.

Jones, R. W., and J. A. Scheinkman (1977) The Relevance of the Two-sector

Production Model in Trade Theory. Journal of Political Economy 85 : 5 909935.

Kuhn, P., and I. Wooton (1987) Immigration and Wages in the Open Economy. Paper presented to the Weekly Trade and Development Workshop at the Economics Department, Columbia University, New York.

Lundahl, M. (1985) International Migration, Remittances, and Real Incomes: Effects on the Source Country. Scandinavian Journal of Economics 87 : 4 647657.

Mahmood, Z. (1989) Emigration, Wages, and Labour Displacement in Pakistan. Unpublished Ph.D. Dissertation submitted to Columbia University, New York. Naqvi, S. N. H., A. H. Khan, N. M. Khilji and A. M. Ahmed (1983) The PIDE Macro-econometric Model of Pakistan's Economy. Islamabad: Pakistan Institute 
of Development Economics.

Pakistan, Government of (Various Issues) Census of Manufacturing Industries.

Karachi: Federal Bureau of Statistics.

Pakistan, Government of (1985) Economic Survey 1985-86. Islamabad: Finance Division, Economic Advisor's Wing.

Pakistan, Government of (1990) Economic Survey 1989-90. Islamabad: Finance Division, Economic Advisor's Wing.

Pakistan, Government of (1971-72 to 1983-84) Labour Force Survey. Karachi: Federal Bureau of Statistics.

Pakistan, Government of (1972-1985) Monthly Statistical Bulletin. Karachi:

Federal Bureau of Statistics.

Rivera-Batiz, F. L. (1982) International Migration, Non-traded Goods and

Economic Welfare in the Source Country. Journal of Development Economics $11: 1$ 81-90.

Ruffin, R. J. (1981) Trade and Factor Movements with Three Factors and Two Goods. Economics Letters $7: 2$ 177-182.

Samuelson, P. A. (1948) International Trade and the Equalisation of Factor Prices.

Economic Journal 58 : 230 163-184. 